E3S Web of Conferences 1, 33002 (2013)

DOI: $10.1051 / \mathrm{e} 3 \operatorname{sconf} / 20130133002$

(C) Owned by the authors, published by EDP Sciences, 2013

\title{
Mobility of Contaminated Heavy Metals and Metalloids in Sediments Caused by Recent Industrial Activities
}

\author{
M. Yoshida ${ }^{1,2}$ \\ ${ }^{1}$ Japan International Cooperation Agency (JICA), 5-25 Nibancho, Chiyoda-ku, Tokyo 102-8012, JAPAN \\ ${ }^{2}$ Department of Environmental Science and Technology, Interdisciplinary Graduate School of Science and Engineering, \\ Tokyo Institute of Technology (TITECH), Yokohama, JAPAN; yoshida.m.ap@m.titech.ac.jp
}

\begin{abstract}
Sequential leaches (sequential extractions) experiment of 62 elements were carried out for assessing the mobility of contaminated heavy metals and metalloids contaminated in natural sediments; river sediments of Oued El Harrach (Algeria) and lagoon sediments of Bizerte (Tunisia), North African Mediterranean coast. Applied extractants for the sequential leaches are: (A) distilled water for extracting water soluble components, (B) $1 \mathrm{M}$ sodium-acetate for extracting exchangeable cations by clay minerals and co-precipitations of carbonates, (C) $0.1 \mathrm{M}$ sodium-pyrophosphate for extracting the elements bound with organic matter, (D) $0.1 \mathrm{M}$ hydroxylamine for extracting the elements bound with amorphous Mn hydroxides, and (E) $0.25 \mathrm{M}$ hydroxylamine for extracting the elements bound with amorphous Fe hydroxides and more crystallized Mn hydroxides. According to the results of sequential leaches experiment, contaminated heavy metals, metalloids, and other potentially toxic element (PTEs) in the sediments are mostly presented as exchangeable cations by clay minerals, co-precipitations of carbonate compounds, binding complexes with organic matter, and/or amorphous manganese hydroxides. Mobility of contaminated heavy metal and metalloids is relatively larger in Algerian river sediment than in Tunisian lagoon sediments. However the mobility of the PTEs in the sediments can be easily changed if the depositional environment is altered by civil construction works.
\end{abstract}

Key words: Industrial pollution, Heavy metals, Sediment contamination, Leaching, North Africa

\section{Introduction}

River, lake, and lagoon bottom sediments located near industrial and urban zones often act as a sink for potentially toxic elements (PTEs; Alloway, 1995) including heavy metals and metalloids, where their concentrations show very high in comparison with the natural background levels. It is well known that the environmental behavior of PTEs, such as their reactivity, mobility, and availability in ecosystems, and biological/ ecological impacts, strongly depends on their particular chemical form. PTEs are contaminated in the sediments as either water soluble species, as structural elements in solids, as adsorbed onto the surface of mineral particles, and/or as bound with organic matters. The PTEs contamination is often the result of industrial/commercial activities or disposal practices. For examples, disposal of batteries results in soil/sediment and water contamination by $\mathrm{Pb}, \mathrm{Cd}$, and $\mathrm{Hg}$; exhaust from automobiles that burn gasoline pollutes air by $\mathrm{Pb}$ particulate and eventually accumulated in sediments; use of pesticides and agro-chemicals results in soil contamination by $\mathrm{Pb}, \mathrm{Hg}$, and As; and mining activities discharges various kinds of heavy metals.

Actually, trace elements have concentrated numerous times in geologic history, which are described by geologists as ore-bodies. All ore-forming processes have in common the mobilization of the metal elements within a large reservoir by some agent such as hydrothermal liquid and the re-deposition in relatively small, high-grade ore-bodies. Weathering and erosion of such bodies at some later stage cause some dispersion of metal elements again. Rivers transport large amounts of dissolved substances to the sea.

Man-made sediment contaminations, environmental pollution, should be similarly considered by the aspect of the equilibrium of material balance in natural sediment. Natural sediments are heterogeneous media that contain a host of different materials; inorganic solid particles and organic materials. Some of contaminated elements are, thus, bonding with such materials, and some elements are easily soluble with water. The former case shows natural 
sink for 'environmental protection' which immobilize toxic contaminants in the sediment, or allows them to enter the biosphere only at a lower concentration level and a lower rate that no harmful effects result. While the latter case permits the contaminated PTEs to mobilize and to merger into a food chain of biosphere through hydrosphere, which provokes environmental pollution problems for ecosystem and human beings. The former to latter case is sometimes easily transformed by the change of environment surrounding the sediments. Thus, the analysis of chemical speciation and mobility of PTEs is crucial factor for making environmental risk assessment.

In this paper, the author report the results of sequential leaches analysis of river and lagoon sediments in Algeria and Tunisia those have been significantly contaminated by heavy metals due to industrial activities.

\section{Material and Method}

\section{Sampling}

The studied site was located in the North African Mediterranean coast, Oued El Harrach river in Algiers, Algeria and Bizerte lagoon in Tunisia. Both sites were located near industrial/urban zones. Seven river sediment samples were collected from Oued El Harrach in April, 2004; OEH-01, 02, 03, 04, 05, 06, \& 07, and four lagoon sediment samples were collected from the bottom sediments of Bizerte lagoon in March, 2002; LB-4L, 11L, $12 \mathrm{~L}, \& 29 \mathrm{~L}$, for the sequential leaches analysis. Detailed information about sampling was reported in Yoshida et al. (2005) for Algerian sites and Ghrabi et al. (2002) for Tunisian sites.

\section{Analytical Procedure}

Sediment samples were dried at room temperature, disintegrated by a porcelain mortar, then sieved through a 250 mesh screen. A $1.0 \mathrm{~g}$ sample split of the finer fraction was used for the analysis. Total 62 elements were measured, $\mathrm{Ag}, \mathrm{Al}, \mathrm{As}, \mathrm{Ba}, \mathrm{Bi}, \mathrm{Ca}, \mathrm{Co}, \mathrm{Cu}, \mathrm{Fe}, \mathrm{K}$, $\mathrm{La}, \mathrm{Mg}, \mathrm{Mn}, \mathrm{Mo}, \mathrm{Na}, \mathrm{Ni}, \mathrm{Pb}, \mathrm{Sb}, \mathrm{Sr}, \mathrm{Th}, \mathrm{Ti}, \mathrm{U}, \mathrm{V}, \mathrm{W}, \mathrm{Zn}$, $\mathrm{Se}, \mathrm{Te}, \mathrm{Au}, \mathrm{Hg}, \mathrm{Be}, \mathrm{Cd}, \mathrm{Ce}, \mathrm{Cs}, \mathrm{Dy}, \mathrm{Er}, \mathrm{Eu}, \mathrm{Ga}, \mathrm{Gd}, \mathrm{Ge}$, Hf, Ho, In, Li, Lu, Nb, Nd, P, Pr, Pt, Pd, Rb, Re, Sc, Sm, $\mathrm{Sn}, \mathrm{Ta}, \mathrm{Tb}, \mathrm{Tl}, \mathrm{Tm}, \mathrm{Y}, \mathrm{Yb}$, and $\mathrm{Zr}$. The analysis of trace element was made using Inductively Coupled Plasma-Atomic Emission Spectrometry (ICP-AES) Parkin Elmer model Plasma Vision 2000 and Mass Spectrometry (ICP-MS) Parkin Elmer model Elan 6000. It is useful to apply sequential leaches or sequential extractions for characterizing the trace element in soil and the state of soil contamination. On the basis of the method developed by Tessier et al. (1979), in present study we used five extractants, A, B, C, D, and E, as follows:
A. Distilled water $\left(\mathrm{H}_{2} \mathrm{O}\right)$ :
B. $1 \mathrm{M}$ sodium-acetate $\left(\mathrm{CH}_{3} \mathrm{COONa}\right)$
C. $0.1 \mathrm{M}$ sodium pyrophosphate $\left(\mathrm{Na}_{4} \mathrm{P}_{2} \mathrm{O}_{7}\right)$

D $\quad 0.1 \mathrm{M}$ hydroxylamine $\left(\mathrm{NH}_{2} \mathrm{OH}\right)$

E $\quad 0.25 \mathrm{M}$ hydroxylamine $\left(\mathrm{NH}_{2} \mathrm{OH}\right)$

The analytical procedure applied is as follows:

(A) At the first step, $1.0 \mathrm{~g}$ sample was prepared from given dried sediment. Then the sample was mixed with $20 \mathrm{~mL}$ distilled neutral water and extracted one hour (Leaching Process A). The mixture was centrifuged and the solution was analyzed. In this process mainly water-soluble component can be extracted.

(B) The residue of above-mentioned 'Leaching Process A' was retained for next leach, Leaching Process $B$, where the sample was mixed with $20 \mathrm{~mL}$ of $1 \mathrm{M}$ sodium-acetate $\left(\mathrm{CH}_{3} \mathrm{COONa}\right)$ solution and the leaching was made for one hour. The mixture was centrifuged and the solution was analyzed. In this process adsorbed and/or exchangeable cations by clay minerals and elements co-precipitated with carbonates are mainly extracted.

(C) The residue of above-mentioned 'Leaching Process B' was retained for next leach, Leaching Process $\mathrm{C}$, where the sample was mixed with $20 \mathrm{~mL}$ of $0.1 \mathrm{M}$ sodium pyrophosphate $\left(\mathrm{Na}_{4} \mathrm{P}_{2} \mathrm{O}_{7}\right)$ solution and the leaching was made for one hour. The mixture was centrifuged and the solution was analyzed. In this process elements adsorbed by organic matter (humic and fulvic compounds) can be extracted.

(D) The residue of above-mentioned 'Leaching Process C' was retained for next leach, Leaching Process $\mathrm{D}$, where the sample was mixed with $20 \mathrm{~mL}$ of $0.1 \mathrm{M}$ hydroxylamine $\left(\mathrm{NH}_{2} \mathrm{OH}\right)$ solution and the leaching was made for one hour. The mixture was centrifuged and the solution was analyzed. This extractant is a reducing reagent, which extracts easily amorphous form of $\mathrm{Mn}$ oxides and hydroxides and the metals associated with them (Ure and Davidson, 1995; Pérez-Sirvent et al., 1999).

(E) The residue of above-mentioned 'Leaching Process D' was retained for next leach, Leaching Process E, where the sample was mixed with $20 \mathrm{~mL}$ of $0.25 \mathrm{M}$ hydroxylamine $\left(\mathrm{NH}_{2} \mathrm{OH}\right)$ solution and the leaching was made for one hour. The mixture was filtered and the solution was analyzed. In this higher concentration $(0.25 \mathrm{M}$ hydroxylamine) treatment elements adsorbed by more crystalline Mn oxides/hydroxides and amorphous Fe hydroxides can be extracted.

According to the interference of leaching agents, $\mathrm{Na}, \mathrm{Cl}$, $\mathrm{Br}, \mathrm{S}$, and $\mathrm{P}$ could be analyzed in limited sequences only.

\section{Results and Discussion}

In order to determine the contribution of each leaching effect among the overall leaches, leaching ratios for each sample was calculated for each element as following equation:

$\mathrm{L}_{\mathrm{X}}=$ [Concentration in Leaching $\left.\mathrm{X}\right]$ / [Sum of concentrations from the Leachings $\mathrm{A}$ to $\mathrm{E}]$ where $\mathrm{X}=\mathrm{A}, \mathrm{B}, \mathrm{C}, \mathrm{D}$, or $\mathrm{E}$. 
Table 1. Summary of Sequential Leaches Experiment of Oued El Harrach (Algeria) river sediment samples. Marked elements are contaminated PTEs caused by industrial/urban activities.

\begin{tabular}{|c|c|c|}
\hline Sequential Leaches Steps & $\begin{array}{l}\text { Elements significantly leached out from } \\
\text { the sediments }\end{array}$ & $\begin{array}{l}\text { Elements relatively leached out from } \\
\text { the sediments }\end{array}$ \\
\hline A (water soluble) & $\mathrm{Li}, \mathrm{Se}$ & $\mathrm{K}, \mathrm{Mo}$ \\
\hline B (exchangeable cations) & $\begin{array}{l}\mathrm{Ca}, \mathrm{La}, \mathrm{Mn}, \mathrm{Pb}, \mathrm{Th}, \mathrm{Hg}, \mathrm{Ce}, \mathrm{Dy}, \mathrm{Er}, \mathrm{Eu}, \\
\mathrm{Gd}, \mathrm{Ho}, \mathrm{Nd}, \mathrm{Pr}, \mathrm{Sm}, \mathrm{Tb}, \mathrm{Y}, \mathrm{Yb}\end{array}$ & $\mathrm{Ba}, \mathrm{Co}, \mathrm{Sr}, \mathrm{U}$ \\
\hline C (organic bounded) & $\begin{array}{l}\mathrm{Ag}, \mathrm{Al}, \mathrm{Cu}, \mathrm{Fe}, \mathrm{K}, \mathrm{Mo}, \mathrm{Sb}, \mathrm{Th}, \mathrm{V}, \mathrm{Hg} \text {, } \\
\mathrm{Be}, \mathrm{Cs}, \mathrm{Rb}, \mathrm{Zr}\end{array}$ & As, U \\
\hline$D$ (amorphous Mn hydroxides) & $\mathrm{As}, \mathrm{Ba}, \mathrm{Pb}, \mathrm{Zn}, \mathrm{Cd}$ & $\begin{array}{l}\mathrm{Ca}, \mathrm{Co}, \mathrm{Fe}, \mathrm{La}, \mathrm{Mn}, \mathrm{Ni}, \mathrm{Sr}, \mathrm{U}, \mathrm{V}, \mathrm{Be} \text {, } \\
\mathrm{Ce}, \mathrm{Dy}, \mathrm{Er}, \mathrm{Eu}, \mathrm{Gd}, \mathrm{Ho}, \mathrm{Nd}, \mathrm{Pr}, \mathrm{Sm} \text {, } \\
\text { Tb, Y }\end{array}$ \\
\hline $\begin{array}{l}\text { E (amorphous Fe hydroxides and } \\
\text { crystalline Mn hydroxides) }\end{array}$ & $\mathrm{Se}$ & $\mathrm{Au}$ \\
\hline
\end{tabular}

Table 2. Summary of Sequential Leaches Experiment of Bizerte lagoon (Tunisia) sediment samples. Marked elements are contaminated PTEs caused by industrial/urban activities.

\begin{tabular}{|l|l|l|}
\hline Sequential Leaches Steps & $\begin{array}{l}\text { Elements significantly leached out from } \\
\text { the sediments }\end{array}$ & $\begin{array}{l}\text { Elements leached out from the } \\
\text { sediments }\end{array}$ \\
\hline$A$ (water soluble) & $\mathrm{Li}, \mathrm{Se}$ & $\mathrm{Mo}$ \\
\hline$B$ (exchangeable cations) & $\begin{array}{l}\mathrm{Sr}, \mathrm{Mg}, \mathrm{K}, \mathrm{La}, \mathrm{Ba}, \mathrm{Mn}, \mathrm{U}, \mathrm{Cd}, \mathrm{Ce}, \mathrm{Zn}, \\
\mathrm{Rb}, \mathrm{Yi}\end{array}$ & $\mathrm{No}, \mathrm{Hg}, \mathrm{Tl}, \mathrm{Pb}$ \\
\hline$C$ (organic bounded) & $\mathrm{Th}, \mathrm{Sn}, \mathrm{Be}, \mathrm{Fe}, \mathrm{Cu}, \mathrm{Ad}$ & $\mathrm{Sb}, \mathrm{As}, \mathrm{V}$ \\
\hline$D$ (amorphous $\mathrm{Mn})$ & $\mathrm{Ag}, \mathrm{V}, \mathrm{Hg}$ & $\mathrm{Mn}, \mathrm{Co}, \mathrm{Ni}, \mathrm{Cd}, \mathrm{Pb}$, and $\mathrm{Tl}$ \\
\hline $\begin{array}{l}\text { E (amorphous Fe hydroxides and } \\
\text { crystalline Mn hydroxides) }\end{array}$ & $\mathrm{Be}, \mathrm{Fe}, \mathrm{Cu}, \mathrm{Al}, \mathrm{Sb}, \mathrm{As}, \mathrm{V}$ & $\mathrm{Cd}, \mathrm{Hg}, \mathrm{Se}, \mathrm{Tl}$ \\
\hline
\end{tabular}

If $\mathrm{Lx}$ is generally larger than 0.5 , it is named as the "significantly leached out from the sediment", and if averaged Lx is generally less than 0.5 but larger than 0.2 , named as the "relatively leached out from the sediment". According to previous researches on sediment contamination in these two sites, the Algerian river sediments in Oued El Harrach were contaminated by heavy metals and metalloids such as $\mathrm{Hg}, \mathrm{Cu}, \mathrm{Pb}, \mathrm{Zn}, \mathrm{Ni}$, $\mathrm{Co}, \mathrm{Mn}, \mathrm{Fe}, \mathrm{As}, \mathrm{Cd}, \mathrm{Sb}, \mathrm{Cr}, \mathrm{Ba}, \mathrm{Al}$, and $\mathrm{Se}$ possibly caused by industrial/urban activities (Yoshida et al., 2005), the Tunisian lagoon sediments in Bizerte were contaminated by heavy metals and metalloids such as $\mathrm{Ba}$, $\mathrm{Pb}, \mathrm{Zn}$, As, Se, Al, Cr, Co, Mn, V, Mo, and $\mathrm{Hg}$ possibly caused by industrial/urban activities (Yoshida et al., 2002). Comparable contamination in Algerian sea sediment was reported by Alomary and Belhadj (2007).

Based on the results of sequential leaches analysis, the mobility of contaminated heavy metals and metalloids in each site is examined as shown in Tables 1 and 2 .

\section{Conclusions}

(1) For the river sediments collected from Oued El Harrach, Algeria, seven samples were analyzed and the general tendency of the pattern of sequential leaches is quite similar. Natural clay minerals and carbonates (lime) play important role for immobilization of contaminated heavy metals and metalloids, such as $\mathrm{Hg}$ and $\mathrm{Ba}$. Organic matters also play very important role for immobilization, in particular for major contaminated heavy metals and metalloids, $\mathrm{Cu}, \mathrm{Sb}, \mathrm{Hg}$, and As. Adsorptions by amorphous manganese hydroxides is effective for immobilizing $\mathrm{As}, \mathrm{Ba}, \mathrm{Pb}, \mathrm{Zn}, \mathrm{Co}$, and $\mathrm{Ni}$.

(2) For lagoon sediments collected from Bizerte lagoon, Tunisia, four samples were analyzed and the general tendency of the pattern of sequential leaches is similar. The lagoon is occupied by sea water, so that salinity probably affects the mobilization of PTEs, where Se and Mo can be mobilized under fresh water condition. Natural clay, carbonates (lime) play very important roles for immobilization of $\mathrm{Ba}, \mathrm{Zn}, \mathrm{Co}, \mathrm{Hg}$, and $\mathrm{Pb}$. On the other hand, organic matters immobilize Al, As, and V. Amorphous manganese hydroxides are effective to immobilize $\mathrm{V}, \mathrm{Hg}, \mathrm{Co}$, and $\mathrm{Pb}$. Immobilization by amorphous iron hydroxides and crystalline manganese hydroxides is also observed for $\mathrm{Sb}, \mathrm{As}, \mathrm{V}$, and $\mathrm{Hg}$.

(3) In general, mobility of contaminated heavy metal and metalloids is relatively larger in Algerian river sediment than in Tunisian lagoon sediments.

(4) Mobility of heavy metals, metalloids, and other PTEs bound with sediments can be easily changed if the river/lagoon bottom environment is altered by civil construction works, for example from anoxic to oxic conditions by dredging. One of the most toxic heavy 
metal $\mathrm{Hg}$ in both sites can be certainly mobilized under a change of conditions. Thus, chemical speciation of PTEs in the sediments of Oued El Harrach is recommended to study prior to implement a counter-measure for de-pollution of river.

\section{Acknowledgements}

The sampling and initial analysis were held as activities of two technical cooperation expert dispatch projects funded by Japan International Cooperation Agency (JICA); the Technical Cooperation Project on Environmental Pollution Monitoring (2004-2006) with the National Observatory of the Environment and Sustainable Development (ONEDD) Algeria, and the Technical Cooperation Project on Waste Management and Environmental Pollution (2000-2002) with the National Institute of Scientific and Technical Researches (INRST) Tunisia. I thank all the project counterparts in ONEDD (Algeria) and INRST (Tunisia). Views expressed in this paper are the author's ones, and not necessarily reflect the official position of JICA.

\section{References}

Alomary, A.A. and Belhadj, S., Mediterranean Sea sediments after a five-stage sequential extraction procedure. Environmental Monitoring and Assessment 2007; 135: 265-280.

Alloway, B.J. (ed.), Heavy Metals in Soils, 2nd Edition. Blackie Academic \& Professional, Chapman \& Hall, London, 368p, 1995.

Tessier, A., Campbell, P.G.C. and Blsson, M., Sequential extraction procedure for the speciation of particulate trace metals. Analytical Chemistry 1979; 51: 844-851.

Ghrabi, A., Yoshida, M., and Shipboard Scientists Team of RPP-SEPMCL leg Bizerte2002, Off-shore Sampling Survey of Bizerte Lagoon, March 2002 Leg-related information and in situ observation data. In Yoshida and Ghrabi (eds.), Study on the Environmental Pollution of Mediterranean Coastal Lagoons in Tunisia (RPP-SEPMCL): Initial Report 2002; 1-12, 2002.

Yoshida, M., Hamdi, H., Ibrahim A. N., and Jedidi, N., Contamination of Potentially Toxic Elements (PTEs) in Bizerte lagoon bottom sediments, surface sediment and sediment repository. In Yoshida and Ghrabi (eds.), Study on the Environmental Pollution of Mediterranean Coastal Lagoons in Tunisia (RPP-SEPMCL): Initial Report 2002; 13-48, 2002.

Yoshida, M., Moari, M. Houas O., Lakhdari M., Nechaoui L., Guerrida D., Chatal A., Oussalem S., Makour F., Khelifi F., and Abderrahmane, L., Environmental Pollution in Oued El Harrach area, Alger -A Preliminary Report on Mercury and Heavy Metals Contaminations-. Compte Rendu du Seminaire sur Pollution et Protection de l'Environnement en Algerie; 19-37, 2005,.

Ure and Davidson, Chemical Speciation in the Environment. Blackie Academic \& Professional, Chapman \& Hall, London, 408p, 1995

Pérez-Sirvent, C., Martínez-Sánchez, J. and García-Rizo, C., Lead mobilization in calcareous agricultural soils. In: Selim, H.M. and Iskandar, I.K. (eds.), Fate and Transport of Heavy Metals in the Vadose Zone. Lewis Publ., Boca Raton, pp.177-199, 1999. 